\title{
Pediatric urodynamics: basic concepts for the neurosurgeon
}

\author{
David M. Kitchens, M.D., C. D. Anthony Herndon, M.D., and David B. JosePh, M.D. \\ Section of Pediatric Urology, University of Alabama Medical Center, Birmingham, Alabama
}

\begin{abstract}
$\checkmark$ A great deal of information about overall bladder and urethral function can be obtained with the utilization of urodynamics. Urodynamics itself does not constitute a single test but more precisely the acquisition of multiple interconnected data combined to give an overall study of the storage and emptying phases of the bladder, function of the urethra, as well as the activity of the pelvic floor musculature. Urodynamic investigation represents one of the few reliable objective tests available to help guide therapy for the neurosurgeon. The authors review the various urodynamic tests most often utilized by pediatric urologists and discuss interpretation pitfalls with respect to interobserver variability. Technical aspects of the study are described along with normal and abnormal findings. (DOI: 10.3171/FOC-07/08/E8)
\end{abstract}

\section{KEY WORDS • electromyography • neurogenic bladder dysfunction • urodynamics}

A BRIEF OVERVIEW of bladder physiology enhances one's ability to understand the utility of urodynamics. The bladder has two primary functions, storage of urine during filling and elimination of urine. Recently obtained data have shown that a normal bladder, even in an infant, does not exhibit any detrusor (bladder) contractions during the filling phase. ${ }^{11}$ In general, the normal bladder will accommodate a predicted volume of urine based on the child's age at a low, or "safe," detrusor pressure. The relationship between the change in bladder capacity and the corresponding change in bladder pressure is referred to as "compliance." The normal bladder is very compliant; that is, there is little change in pressure going from an empty bladder to a maximal capacity as predicted for age. The newborn bladder has a predicted capacity of approximately 20 to $30 \mathrm{ml} .^{1,11,13}$ A child's bladder capacity is predicted by using one of several formulas (for example, age in years $+2=$ no. of ounces $\times 30=$ no. of milliliters) ${ }^{6}$ Knowing the predicted bladder capacity is necessary when interpreting urodynamic results.

The normal voiding phase begins with volitional relaxation of the perineum and external urinary sphincter followed by opening of the bladder neck. This process initiates a reflex bladder contraction and expulsion of urine at low pressure. This voiding pattern is synergic coordination among the bladder neck, external sphincter, and detrusor muscle. An infant initiates the normal voiding phase through reflex stimulation of touch, temperature, and bladder filling. In children with abnormal neurogenic bladder function, the detrusor may contract before relax-

Abbreviation used in this paper: $\mathrm{EMG}=$ electromyography. ation of the bladder neck and external urinary sphincter, resulting in high pressure voiding called "detrusor-sphincter dyssynergy." Normally the bladder will empty to completion with a single contraction. A postvoid residual of more than $5 \mathrm{ml}$ in the neonate and greater than $10 \%$ of the expected capacity in the older child is considered abnormal. ${ }^{3,4}$

\section{Urodynamic Tests: Noninvasive}

In the strictest sense, urodynamic testing can be divided into noninvasive and invasive procedures. Noninvasive testing includes uroflowmetry (the volume of urine expelled per second) and postvoid residual. Uroflowmetry requires a potty-trained child who can void into a container on command. The voided volume, voiding time, and peak voiding velocity are recorded. A postvoid residual is estimated using a simple ultrasonography device. This test can be enhanced by attaching surface EMG electrodes around the perineum to simultaneously record its activity while voiding. Although these noninvasive tests can be utilized to screen for obstructive urinary disorders, their value in formulating an actual diagnosis with regard to neurogenic bladder dysfunction is very limited, and invasive testing is required.

\section{Urodynamic Tests: Invasive}

Invasive urodynamics requires urethral catheterization and the placement of a rectal catheter to measure abdominal pressure and often needle electrodes for sphincter EMG. This process carries the risk of pain, hematuria, infection, and possible urinary retention. ${ }^{10}$ Pretest family and patient education helps to reduce anxiety. 
D. M. Kitchens, C. D. A. Herndon, and D. B. Joseph

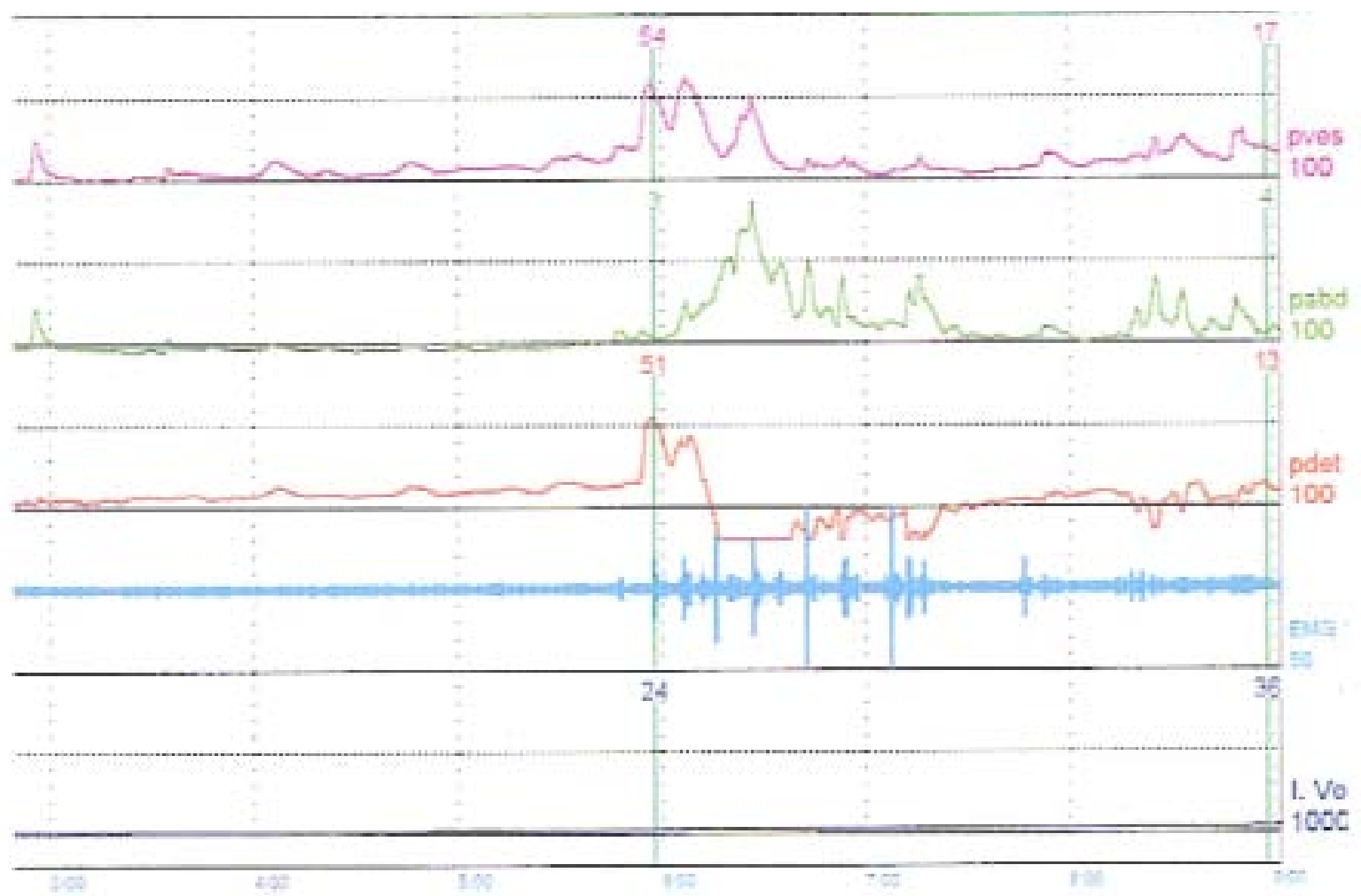

FIG. 1. Tracings showing a minimal change in pressure of $P_{\text {det }}$ until initiation of voiding at a corrected pressure of 51 $\mathrm{cm} \mathrm{H}_{2} \mathrm{O}$. A minimal increase in the EMG recordings at the time of voiding can be normal in an infant. All 100s on the $y$ axis (pves, pabd, pdet) refer to maximum pressure measurable on graph, which is $100 \mathrm{~cm}_{2} \mathrm{O}$. The 50 on the y axis refers to the maximum EMG potential, which is $50 \mathrm{mV}$. The $\mathrm{x}$ axis represents time. I. Vol = volume of fluid infused in bladder, $1000 \mathrm{ml}$ is maximum volume.

Testing is initiated with the patient in a supine position on a table that may accommodate fluoroscopic imaging during the evaluation. Rectal tone is assessed, and a rectal balloon catheter is inserted. Most often a dual-lumen transurethral catheter is placed. Some situations can call for suprapubic placement. Electromyography electrodes, in the form of a surface gel pad, wires, or a needle, are placed on or in the perineum. The surface gel pad has the advantage of providing little discomfort to the patient, but its accuracy is limited and represents all perineal activity. ${ }^{10}$ The wire or needle electrodes are more specific for external sphincter activity but do cause momentary pain with placement; regardless, either device provides for perineal sensory assessment.

\section{Cystometric Analysis}

Bladder dynamics and function are recorded in cystometry. The bladder is filled with either an isotonic solution or a contrast medium at room or body temperature. The bladder filling rate is an important variable that influences the reliability of data and must be controlled in a uniform and consistent fashion. ${ }^{5}$ Typically, the bladder is filled at a rate that does not exceed $10 \%$ per minute of the patient's predicted bladder capacity. A rectal balloon catheter is used to measure the pressure of the abdominal cavity, $\mathrm{P}_{\text {abd }}$. The urethral catheter is used to measure the total pressure inside the bladder, $P_{\text {ves }}$. A child who is moving, coughing, or crying will indirectly affect the bladder pressure; ${ }^{11}$ therefore, a corrected detrusor pressure $\left(\mathrm{P}_{\mathrm{det}}\right)$ is generated to account for this artifact. The $\mathrm{P}_{\text {det }}$ is calculated with the formula $\mathrm{P}_{\text {ves }}-\mathrm{P}_{\text {abd }}$. The $\mathrm{P}_{\text {det }}$ is used to determine whether pressures in the bladder are "safe" or "hostile." Additionally, abdominal pressure recording is useful during the voiding phase to identify straining, or the Valsalva maneuver as a technique to eliminate urine. Measurements of perineal EMG occur simultaneously with the evaluation of synergy or dyssynergy. The cystometric analysis is continued through several voiding cycles, either to the point of continuous leakage or once a capacity in excess of the predicted capacity is achieved. There are limitations in determining pressures while leaking or voiding around a urethral catheter is occurring, especially in a neonate with a small-caliber urethra. ${ }^{14}$

\section{Videourodynamic Studies}

Some investigators conduct videourodynamic studies, which incorporate fluoroscopic imaging while performing cystometry. Information gathered is invaluable and includes assessments of the bladder wall, bladder neck, external urinary sphincter coordination, and vesicoureteral reflux. This data helps support the interpretation of results, especially when sphincter dyssynergy is suspected.

\section{Urodynamic Interpretations and Their Pitfalls}

Normal bladder filling through the predicted bladder capacity according to age should occur without a significant 


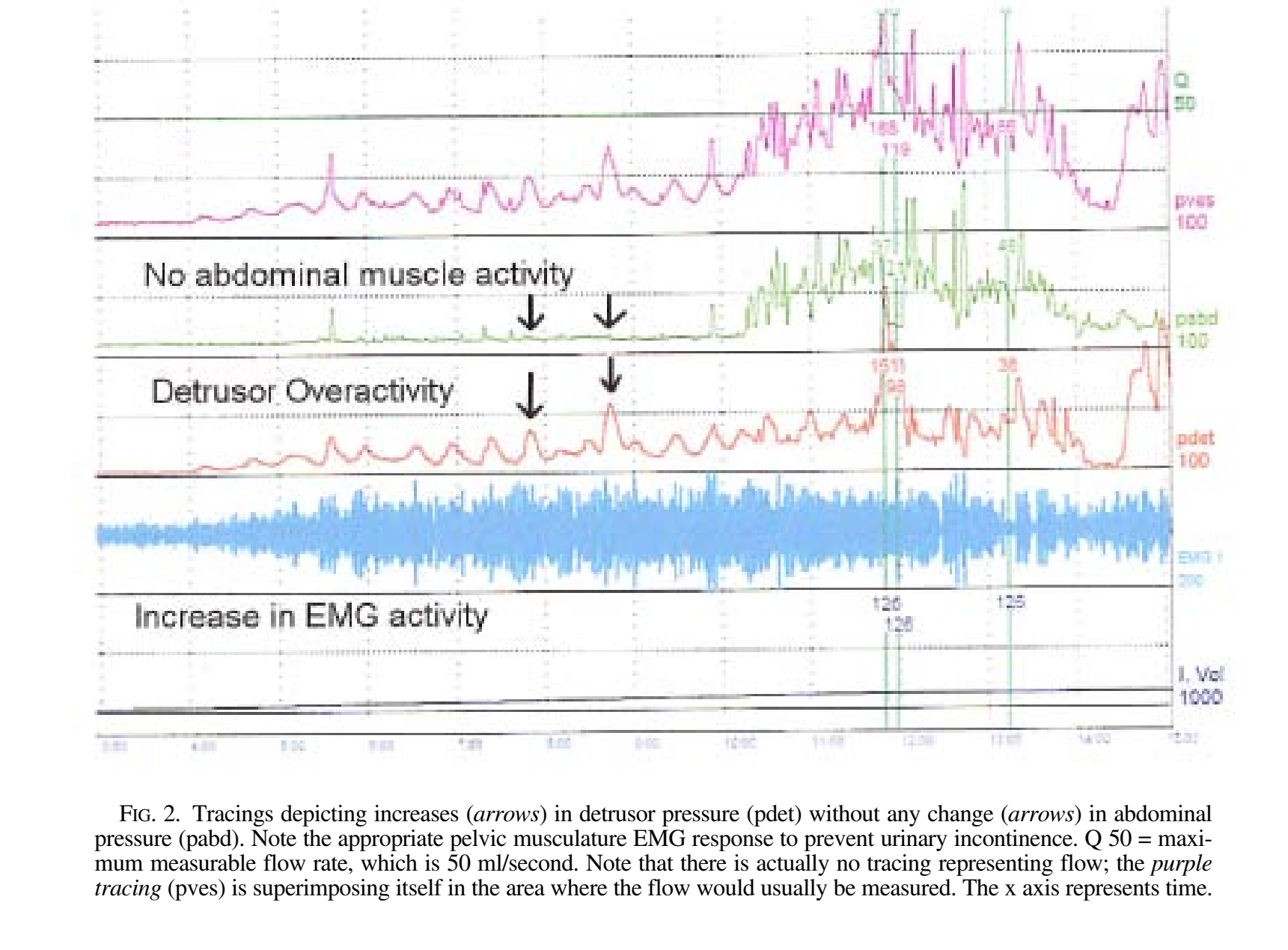

rise in $\mathrm{P}_{\text {det }}$ and without any bladder contractions (Fig. 1). Any detrusor contraction prior to volitional voiding constitutes overactivity and is considered abnormal (Fig. 2), ${ }^{8}$ but this occurrence can be difficult to discern in an infant. It is well established that a sustained filling pressure $\left(\mathrm{P}_{\text {det }}\right)$ in excess of $40 \mathrm{~cm} \mathrm{H}_{2} \mathrm{O}$ causes upper urinary tract damage, creating a "hostile" bladder environment." Therapeutic measures are initiated to maintain a "safe" bladder pressure (that is, less than $40 \mathrm{~cm} \mathrm{H}_{2} 0$ ) during bladder filling.

The child's age plays a significant role in the interpretation of data. Neonates tend to void more frequently and at a higher pressure than older children; $;^{2,11}$ this pattern occurs even when accounting for the size of the catheter. Moreover, an increase in EMG action potential during voiding can be a normal finding up to the age of 2 years, but is considered abnormal thereafter (Fig. 3). ${ }^{11}$ Therefore, a study result can be considered normal at one age and dysfunctional at another.

As with almost any other diagnostic examination, certain principles or disclaimers apply specifically to urodynamic tests. The failure to record an abnormality during urodynamic testing does not rule out its existence. ${ }^{9}$ Moreover, not all detected abnormalities are necessarily clinically significant. Interestingly, interobserver variability with regard to the assessment of pediatric urodynamic data recently was marked by a discrepancy among pedi- atric urologists at different institutions, indicating a lack of standardization in technique and interpretation. ${ }^{12}$

\section{Conclusions}

Urodynamic testing, when undertaken in a consistent and systematic fashion, is reliable and reproducible. It offers the only objective measurement of bladder function and neurogenic dysfunction.

\section{References}

1. Bachelard M, Sillen U, Hansson S, Hermansson G, Jodal U, Jacobsson B: Urodynamic pattern in asymptomatic infants: siblings of children with vesicoureteral reflux. J Urol 162: 1733-1738

2. Hjalmas K: Urodynamics in normal infants and children. Scand J Urol Nephrol Suppl 114:20-27, 1988

3. Holmdahl G, Hanson E, Hanson M, Hellström AL, Sillén U, Sölsnes E: Four-hour voiding observation in healthy infants. J Urol 156:1809-1812, 1996

4. Johnston JH, Harrison N: Investigation of bladder function, in Williams DI, Johnston JH (eds): Pediatric Urology, ed 2. London: Butterworth Scientific, 1982, pp 215-224

5. Joseph DB: Urodynamics in the pediatric population: indications and techniques, in Elder JS (ed): Pediatric Urology for the General Urologist. New York: Igaku-Shoin, 1996, pp $188-201$ 
D. M. Kitchens, C. D. A. Herndon, and D. B. Joseph

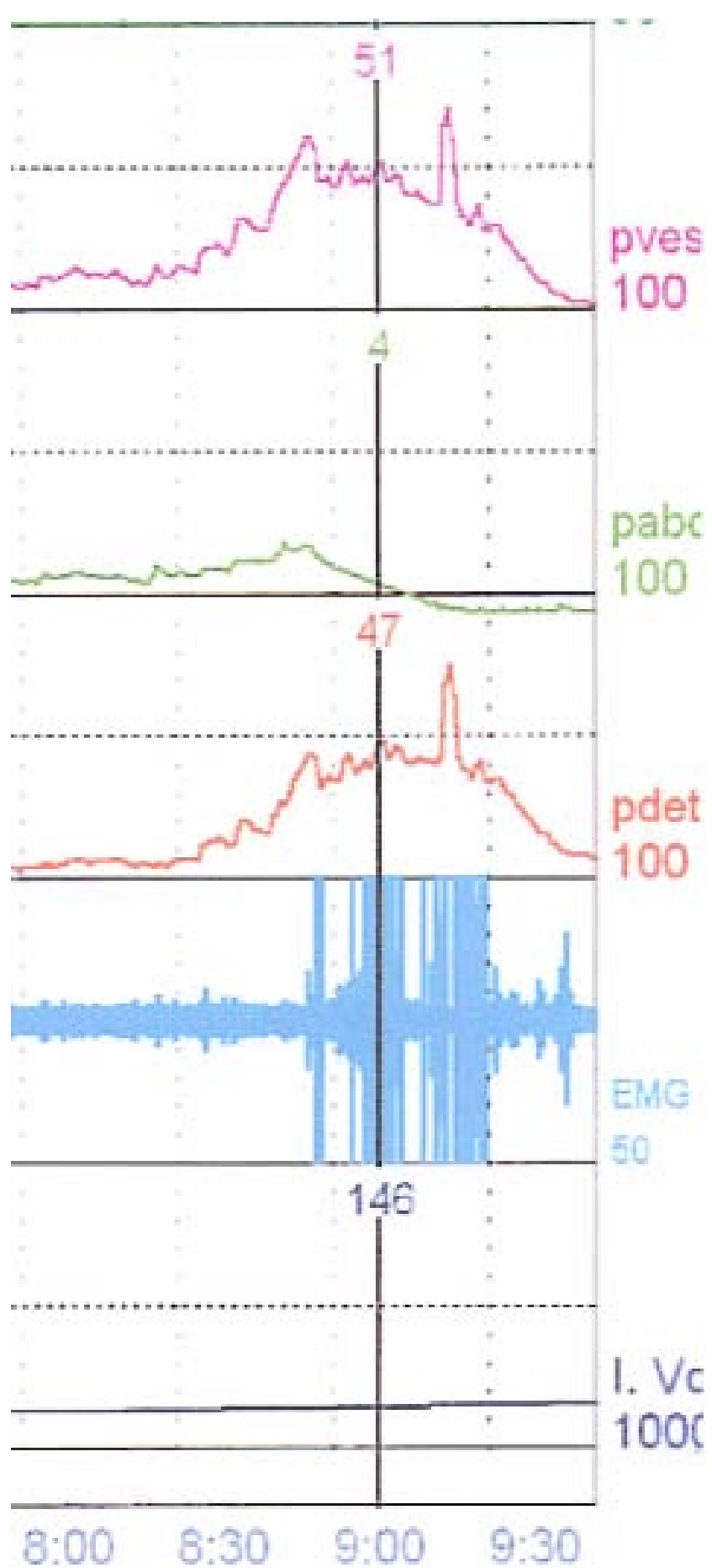

FIG. 3. Tracings showing an increase in EMG activity while voiding is initiated. This finding can be normal until the age of 2 years, but a sign of dysfunction thereafter. The $\mathrm{x}$ axis represents time.

6. Koff SA: Estimating bladder capacity in children. Urology 21: 248, 1983

7. McGuire EJ, Woodside JR, Borden TA, Weiss RM: Prognostic value of urodynamic testing in myelodysplastic patients. J Urol 126:205-209, 1981

8. Nevéus T, von Gontard A, Hoebeke P, Hjälmås K, Bauer S, Bower W, et al: The standardization of terminology of lower urinary tract function in children and adolescents: report from the Standardisation Committee of the International Children's Continence Society. J Urol 176:314-324, 2006

9. Nitti VW, Combs AJ: Urodynamics: when, why and how, in Nitti VW (ed): Practical Urodynamics. Philadelphia: WB Saunders, 1998, pp 15-26

10. Peterson AC, Webster GD: Urodynamic and videourodynamic evaluation of voiding dysfunction, in Wein AJ, Kavoussi LR, Novick AC, Partin AW, Peters CA (eds): Campbell-Walsh Urology, ed 9. Philadelphia: Saunders, 2007, pp 1986-2010

11. Sillen U: Bladder function in infants. Scand J Urol Nephrol Suppl 215:69-74, 2004

12. Venola M, Reunanen M, Taskinen S, Lahdes-Vasama T, Uhari $\mathrm{M}$ : Interobserver and intra-observer agreement in interpreting urodynamic measurements in children. J Urol 169:2344-2346, 2003

13. Wen JG, Tong EC: Cystometry in infants and children with no apparent voiding symptoms. Br J Urol 81:468-473, 1998

14. Yeung CK, Sihoe J, Bauer SB: Voiding dysfunction in children: non-neurogenic and neurogenic, in Wein AJ, Kavoussi LR, Novick AC, Partin AW, Peters CA (eds): Campbell-Walsh Urology, ed 9. Philadelphia: Elsevier, 2007, pp 3604-3655

Manuscript submitted June 14, 2007.

Accepted July 13, 2007.

Address reprint requests to: David M. Kitchens, M.D., 1600 Seventh Avenue South, Birmingham, Alabama 35233-1711. email: david.kitchens@ccc.uab.edu. 